\title{
ANALISIS KERJA DAN KUALITAS PELAYANAN CONCIERGE TERHADAP KEPUASAN TAMU GRAND EDGE HOTEL
}

\author{
Oleh \\ Azis Nur Rosyid ${ }^{1)}$ \& Artin Bayu Mukti²) \\ 1,2 Universitas Stikubank (UNISBANK) Semarang \\ Email: 1aziz_fpar@edu.unisbank.ac.id \&2bayu_fpar@edu.unisbank.ac.id
}

\begin{abstract}
Abstrak
Penelitian ini dilakukan untuk mengnalisis prosedur kerja dan kualitas pelayanan concierge terhadap kepuasan tamu di Grand Edge Hotel Semarang. Metode penelitian yang digunakan yaitu deskriptif, dengan jenis penelitian kualitatif. Data diperoleh dari hasil kuisioner yang dibagikan ke seluruh tamu serta wawancara secara langsung dengan staf Concierge Grand Edge Hotel Semarang, selain itu juga didukung dengan beberapa dari studi pustaka dan observasi. Data yang diperoleh dijelaskan secara kualitatif dan dijelaskan dalam bentuk uraian yang disusun secara detail dan sistematis.
\end{abstract}

\section{Kata Kunci: Prosedur Kerja, Kualitas Pelayanan \& Kepuasan Tamu}

\section{PENDAHULUAN}

Industri pariwisata Indonesia telah menjadi salah satu sumber pendapatan Negara kedua setelah migas, sehingga dapat dikatakan bahwa industri pariwisata menjadi salah satu alternatif penumbuhan dan pemulihan perekonomian bangsa Indonesia. Oleh karena itu sudah sepantasnya kita memberikan perhatian khusus terhadap keberadaan pariwisata.

Sehubungan dengan itu semua maka diciptakanlah suatu industri pariwisata serta disediakannya sarana akomodasi yang disebut dunia perhotelan guna menunjang kepariwisataan di Indonesia. Di dalam dunia perhotelan wujud dari pengembangan kebudayaan dituangkan dalam suatu wadah yang mencerminkan kebudayaan itu sendiri, salah satunya ialah didirikanlah sarana akomodasi yang disebut hotel. Di mana sarana akomodasi ini dikelola secara komersial yang menghasilkan barang dan jasa serta manajemen untuk memberikan pelayanan terbaik pada tamu agar mencapai kepuasan yang

diinginkan dengan berpedoman pada kebudayaan sendiri tanpa menyampingkan kebudayaan lain.

Concierge berperan penting terhadap kepuasan dan kenyamanan tamu, dalam hal membawakan barang bawaan tamu pada waktu check in atau check out, melakukan penjemputan tamu di bandara maupun stasiun kereta api. Oleh sebab itu, Concierge harus mengikuti SOP (Standard Operating Procedure) guna meningkatkan kerja dan kesan positif.

Di Grand Edge Hotel, walaupun jumlah Concierge sedikit namun mereka tetap aktif dalam melayani tamu-tamu yang berkunjung di hotel. Mereka tak kenal lelah dalam memberikan pelayanan yang prima dan menjunjung tinggi profesionalisme dalam bekerja.

Berdasarkan permasalahan diatas, maka rumusan masalah sebagai berikut:

1. Bagaimana prosedur kerja Concierge di Grand Edge Hotel Semarang?

2. Bagaimana kualitas pelayanan Concierge di Grand Edge Hotel Semarang?

3. Bagaimana kepuasan tamu di Grand Edge Hotel Semarang?

\section{LANDASAN TEORI Konsep Hotel}

Dilihat dari asal katanya, perkataan hotel berasal dari bahasa latin Hospes yang mempunyai pengertian untuk menunjukkan orang asing yang menginap di rumah seseorang (teman, kenalan, atau musafir yang dihormati). Kemudian dalam perkembangannya kata Hospes menjadi hotel dalam Bahasa Perancis, 
dan seterusnya menjadi hotel dengan pengertian sebagai rumah penginapan. (Suarthana, 2006:11)

Menurut Sugiarto (2002:23) Hotel merupakan sebuah gedung yang digunakan untuk tempat penginapan dengan tujuan komersial dan menyediakan jasa pelayanan secara professional bagi tamu termasuk penyediaan makanan, minuman dan fasilitas lainnya.

Sedangkan menurut Arief (2005:7) hotel adalah suatu akomodasi yang menyediakan tempat atau kamar, dimana orang-orang atau pengunjung atau wisatawan dapat beristirahat / menginap / tidur, mandi, makan dan minum serta menikmati jasa pelayanan dan hiburan yang tersedia.

Walaupun pengertian hotel menurut para ahli berbeda-beda, namun mempunyai satu tujuan yang sama yaitu layanan jasa.

\section{Konsep Front Office Department}

Menurut Sihite (2000:8) pengertian Front Office yaitu Kantor depan pada sebuah hotel adalah bagian atau departemen yang bertanggung jawab dalam penjualan kamar hotel baik melalui pemesanan (reservation) sebelumnya maupun tanpa pemesanan, dilanjutkan dengan pendaftaran (registration) dan penunjukan kamar (room assignment) bagi tamu.

Sedangkan menurut Arief (2005:113), Front Office Department yaitu bagian kantor depan hotel yang bertugas menerima reservasi, menangani bagasi tamu yang check-in dan check-out, memberikan informasi, menerima dan mengakomodasi tamu yang check-in, membuat rekening perhitungan biaya tamu, membuat laporan administrasi penjualan kamar seperti house count / room count sheet, room sales recapitulation, guest room statistic, dan sebagainya.

Jadi Front Office Department mempunyai beberapa peranan penting dalam sebuah hotel yaitu menjadi jantung hotel, memiliki peran sebagai penjual, peran sebagai administrator, koordinator pelayanan, sebagai sumber informasi, dan pembentuk citra (image).

\section{Konsep Concierge}

Seperti dijelaskan oleh Darsono dalam bukunya Kantor Depan Hotel (2001:74), Concierge adalah salah satu seksi yang ada di bawah Front Office Department yang mempunyai tugas utama membawakan barang bawaan tamu pada waktu check-in dari mobil ke kamar dan membawakan barang bawaan tamu pada waktu check-out dari kamar ke mobil. Secara garis besar, ruang lingkup adalah memberikan pelayanan penanganan barang bawaan tamu tiba, penanganan barang pindah kamar, dan penanganan barang tamu berangkat, memberikan pelayanan penjemputan dan pengantaran tamu dari dan ke stasiun atau bandar udara, memberikan pelayanan penyampaian pesan tamu, informasi, dan kunci kamar dan melaksanakan tugas-tugas suruhan lain yang berkaitan dengan pelayanan tamu (errand service).

Sedangkan menurut Suarthana (2006:27) dalam buku yang berjudul Manajemen Perhotelan edisi Kantor Depan yang berarti bahwa bekerja sebagai Concierge memiliki arti yang mana fokus kita adalah memastikan segala kebutuhan dan permintaan tamu bisa terpenuhi dan setiap tamu memiliki kenangan yang baik selama mereka tinggal. Pelayanan Concierge yang diberikan tidak terbatas hanya pada pelayanan atau penyimpanan barang, lebih dari itu seorang Concierge harus paham dan memiliki pengetahuan yang luas mengenai hotel dan lokal area di luar hotel. Tamu akan datang dan mendekati Concierge dengan membawa pertanyaan, mencari saran dan berbagai macam permintaan solusi masalah.

\section{Standar Operasional Prosedur (SOP)} Concierge

Dalam hal ini SOP yang harus diperhatikan dalam concierge yang bersumber dari http://docslide.us/documents/sopconcierge.html\# meliputi:

1. Bellboy Script for Guest Rooming

1) Standar

Tamu harus menerima sebagian besar informasi tentang hotel pada saat kedatangan mereka dan dikawal ke 
kamar mereka dengan pengawalan menjelaskan hotel dan fasilitas kamar.

2) Tujuan Agar tamu memiliki informasi hotel dan tidak kesulitan menggunakan fasilitas hotel.

3) Prosedur

Pada saat kedatangan di kamar,dahuluilah untuk membukakan pintu dan masuk dalam kamar kemudian nyalakan semua lampu dan fasilitas yang ada dalam kamar untuk memastikan semuanya baik-baik saja dan tidak ada masalah. Jika ada masalah segera menghubungi bagian engineering agar sesegera mungkin diatasi, jika tidak ada masalah semuanya terkendali letakan barang barang tamu di meja barang kemudian mulai menjelaskan tentang fasilitas yang ada di kamar.

2. Airline / Train / Bus Reservation

1) Standar

Airline / train / bus reservation, semuanya akan di atasi oleh Concierge.

2) Tujuan

Memberikan informasi tentang penjemputan tamu.

3) Prosedur

Arahkan tamu ke bagian counter Concierge, lalu bertanya tentang penjemputan di bandara / stasiun / pemesanan bis. Jangan lupa selalu greeting kepada tamu. Setelah tamu memilih keputusan untuk memilih jenis transportasinya, Concierge akan membuatkan reservation ke bagian kantor transportasi yang ada di hotel.

\section{Airport Transportation}

1) Standar

Concierge mengatur transportasi bandara atas permintaan dan selalu memberikan tamu konfirmasi atas aturan yang dibuat dan selalu mengupdate jadwal transportasi ke bandara. Untuk biaya dan waktunya semua terserah tamu yang menentukan.

2) Tujuan
Untuk memberikan informasi yang cukup tentang jenis transportasi ke bandara dan dapat di atur sesuai keinginan tamu.

3) Prosedur

(1) Memastikan keinginan tamu untuk mode transportasi ke bandara

(2) Menawarkan bentuk bentuk alternatif transportasi seperti taksi dan mobil hotel.

(3) Memberitahu tamu akan biaya dan waktu yang diperlukan untuk perjalanan dari hotel ke bandara.

(4) Memperbaharui informasi transportasi bila diperlukan, pastikan semua informasi tentang transportasi sudah tercantum dalam buku.

(5) Jangan lupa untuk mendata tamu yang berminat untuk pengantaran ke bandara, kemudian untuk diserahkan ke Front Office.

(6) Fasilitas shuttle service dari hotel sepenuhnya gratis.

\section{Luggage Handling}

1) Standar

Kebijakan hotel untuk membantu semua tamu dengan barangnya. Ini termasuk membantu membawakan barang pada saat check in, check out, penitipan barang dan penyimpanan barang.

2) Tujuan

Untuk menghindari tamu membawa barangnya sendiri yang bertujuan memberikan tamu kepuasan.

3) Prosedur

(1) Setelah tamu tiba di hotel, Bellboy menyerahkan luggage tag ke tamu yang berminat barangnya dibawakan, agar barang tidak salah orang.

(2) Untuk barang yang di titipkan, Bellboy menyimpannya di luggage room, dan untuk pengambilannya nanti tamu akan menyerahkan potongan tag dengan nomor yang sama seperti yang ada pada barang yang ditipkan 
(3) Setelah meletakkan barang tamu ke meja barang yang ada di kamar, Bellboy akan menjelaskan tentang fasilitas yang ada di kamar.

(4) Ketika Bellboy menggambil barang barang tamu yang akan check out, Bellboy akan memberi no. tag kepada tamu, sama seperti pada saat check in

5. Luggage Handling 2

1) Standar

Menghindari kehilangan barang, terkadang bisa terjadi kesalahan karena terlalu banyak tamu yang menumpuk pada saat check in dan terlalu banyak barang yang harus di atasi oleh Concierge.

2) Tujuan

Untuk memastikan barang sampai kepada pemiliknya di kamar.

3) Prosedur

(1) Semua barang harus ada no. tag nya dan potongan tag tersebut di tangan tamu.

(2) Jangan lupa menanyakan nomor kamar kepada tamu dan mengkonfirmasikan barang tamu yang mana.

(3) Mengantarkan barang tamu sesuai dengan kamar dan no. tag.

\section{Lobby Appearance}

1) Standar

Concierge juga bertugas memantau area lobby dan ikut membantu menjaga keindahan lobby dengan bekerja sama dengan public area.

2) Tujuan

Untuk membantu Housekeeping menjaga kebersihan area lobby sebersih mungkin.

3) Prosedur

(1) Mengelilingi area lobby ketika hotel sedang sepi, dan memberitahukan kepada Housekeeping jika ada yang perlu dibersihkan.

(2) Laporkan kepada Housekeeping semua yang perlu di bersihkan.

7. Luggage Tag
1) Standar

No. tag harus ada di barang tamu, dan potongan tag harus diberikan kepada tamu, Bellboy harus mempunyai minimal 5 tag di dalam sakunya.

2) Tujuan

Untuk menghindari terjadinya kesalahan pengiriman barang ke kamar tamu.

3) Prosedur

(1) Ketika tamu memberikan barang ke Bellboy sesegera lah memberi tamu potongan tag yang sesuai dengan barang tamu tersebut.

(2) Tuliskan nama tamu ke luggage tag yang ada di barang tamu.

(3) Tata barang tamu di trolley dan tunggu tamu sampai tamu dapat kamar dan perintah dari tamu untuk mengirim barangnya ke kamar tamu.

\section{Konsep Kualitas Pelayanan}

Pada dasarnya kualitas pelayanan mengandung beberapa aspek yang harus dikuasai oleh karyawan yaitu kemampuan yang profesioanl dan teguh serta sikap yang tulus ikhlas, senang membantu, menyelesaikan kepentingan, keluhan, dan memberikan pelayanan yang terbaik. Berikut ada tiga konsep dasar (A3) yang bersumber dari http://apkexcellent.blogspot.co.id/2013/06/kon sep-dasar-pelayanan-prima.html harus diperhatikan dalam mewujudkan pelayanan, yaitu :

1. Konsep Sikap (attitude)

1) Sikap pelayanan yang mempunyai rasa kebanggaan terhadap pekerjaan.

2) Memiliki pengabdian besar terhadap pekerjaan.

3) Serta senantiasa menjaga martabat dan nama baik perusahaan.

2. Konsep Perhatian (attention)

1) Mengucapkan salam pembuka pembicaraan.

2) Menanyakan apa saja keinginan tamu / pelanggan

3) Mendengarkan dan memahami keinginan tamu / pelanggan.

4) Melayani cepat, tepat, dan ramah. 
3. Konsep Tindakan (action)

1) Segera mencatat pesan/keinginantamu.

2) Menegaskan kebutuhan/pesanan tamu.

3) Mengucapkan terima kasih diiringi harapan supaya tamu akan kembali lagi. Menurut Lupiyoadi (2001:148) bahwa tamu akan menilai kualitas pelayanan melalui lima prinsip, yaitu :

1. Tangibles (bukti fisik) yaitu kemampuan suatu perusahaan dalam menunjukkan eksistensinya kepada pihak eksternal. Penampilan dan kemampuan sarana dan prasarana fisik perusahaan dan keadaan lingkungan sekitarnya adalah bukti nyata dari pelayanan yang diberikan oleh pemberi jasa, yang meliputi fasilitas fisik (gedung, gudang, dan lain sebagainya), perlengkapan dan peralatan yang dipergunakan (teknologi), serta penampilan pegawainya.

2. Reliability (kehandalan) yaitu kemampuan perusahaan untuk memberikan pelayanan sesuai yang dijanjikan secara akurat dan terpercaya. Kinerja harus sesuai dengan harapan pelanggan yang berarti ketepatan waktu, pelayanan yang sama untuk semua pelanggan tanpa kesalahan, sikap yang simpatik, dan dengan akurasi yang tinggi.

3. Responsiveness (ketanggapan) yaitu kemauan untuk membantu dan memberikan pelayanan yang cepat (responsif) dan tepat kepada tamu, dengan penyampaian informasi yang jelas.

4. Assurance (jaminan dan kepastian) yaitu pengetahuan, kesopansantunan, dan kemampuan para pegawai perusahaan untuk menumbuhkan rasa percaya para pelanggan kepada perusahaan. Terdiri dari beberapa komponen antara lain komunikasi, kredibilitas, keamanan, kompetensi, dan sopan santun.

5. Emphaty (empati) yaitu memberikan perhatian yang tulus dan brsifat individual atau pribadi yang diberikan kepada para tamu dengan berupaya memahami keinginan tamu. Dimana suatu perusahaan diharapkan memiliki pengertian dan pengetahuan tentang pelanggan, memahami kebutuhan pelanggan secara spesifik, serta memiliki waktu untuk pengoperasian yang nyaman bagi tamu.

\section{Konsep Kepuasan Tamu}

Menurut Sulastiyono

(2008:33),

kepuasan tamu dapat diartikan sebagai suatu keadaan dalam diri seseorang, dimana dia telah berhasil mendapatkan sesuatu yang menjadi kebutuhan-kebutuhan dan keinginankeinginannya. Sedangkan keinginan dapat diartikan sebagai suatu kondisi seseorang yang merasakan kekurangan terhadap sesuatu yang lazim bagi dirinya.

Sedangkan menurut Suwarman (2003:35), kepuasan adalah tingkat perasaan setelah membandingkan kinerja / hasil yang dirasakan dengan harapannya. Jadi tingkat kepuasan merupakan fungsi dari perbedaan antara kinerja yang dirasakan harapan. Apabila kinerja dibawah harapan maka tamu akan kecewa, sebaliknya bila kinerja sesuai harapan maka tamu akan puas.

Menurut Dimyati (1989 : 89-90) kepuasan tamu setelah menginap di hotel dapat terwujud apabila tamu tersebut dari awal datang hingga tamu itu pergi mendapatkan pelayanan yang memuaskan seperti :

1. Cepat dan tepat dalam melayani tamu

2. Memberikan informasi hotel yang jelas dan benar.

3. Memberikan senyuman yang tulus.

4. Memberikan bantuan pada tamu sebelum diminta.

5. Memanggil atau menuliskan nama tamu dengan benar.

6. Memperhatikan sikap dan tindakan bahwa tamu adalah penting bagi hotel.

7. Mengucapkan Greeting atau salam pada tamu saat tertentu.

Dalam hal meningkatkan kepuasan tamu, terdapat lima faktor yang harus diperhatikan oleh perusahaan (Lupiyoadi, 2001 : 140) antara lain:

1. Kualitas produk, yaitu tamu akan merasa puas bila hasil mereka menunjukkan bahwa produk yang mereka gunakan berkualitas.

2. Kualitas pelayanan atau jasa, yaitu tamu akan merasa puas bila mereka mendapatkan pelayanan yang baik atau sesuai dengan yang diharapkan 
3. Emosi, yaitu tamu akan merasa bangga dan mendapatkan keyakinan bahwa orang lain akan kagum terhadap dia bila menggunakan produk dengan merek tertentu yang cenderung mempunyai tingkat kepuasan yang lebih tinggi.

4. Harga, yaitu produk yang mempunyai kualitas yang sama tetapi menetapkan harga yang relatif murah akan memberikan nilai yang lebih tinggi kepada tamu.

Biaya, yaitu tamu yang tidak perlu mengeluarkan biaya tambahan atau tidak perlu membuang waktu untuk mendapatkan suatu produk atau jasa cenderung puas terhadap produk atau jasa tersebut.

\section{METODE PENELITIAN}

\section{Tipe Penelitian}

Penulis menggunakan metode deskriptif yaitu untuk melukiskan secara sistematis, fakta atau karakteristik populasi tertentu atau bidang tertentu, dalam hal ini bidang secara aktual dan cermat. (Hasan, 2004:22).

\section{Spesifikasi Penelitian}

Menggunakan metode deskriptif kualitatif yaitu penelitian yang berusaha mendeskrisikan atau menggambarkan atau melukiskan fenomena atau hubungan antar fenomena yang diteliti secara sistematis, faktual dan akurat. (Sugiarto dan Kusmayadi, 2000:29).

\section{Sumber Data}

Data Primer

Penulis mengumpulkan data dari kuisioner tamu sebanyak 30 responden pada bulan Mei 2019 di Grand Edge Hotel Semarang.

\section{Data Sekunder}

Penulis mendapatkan data dari bukubuku referensi yang mendukung tentang prosedur kerja Concierge, kualitas pelayanan serta kepuasan tamu.

\section{Metode Pengumpulan Data} yaitu:

Menggunakan teknik pengumpulan data
A. Wawancara langsung (interview)

Penulis memberikan pertanyaan terhadap staff Front Office Department khususnya
Concierge mengenai Kualitas Pelayanan Concierge di Grand Edge Hotel Semarang.

B. Observasi atau pengamatan

Mengamati bagaimana operasional dari Concierge di Grand Edge Hotel Semarang.

C. Studi Pustaka

Menggunakan buku-buku yang menunjang tentang kinerja Concierge yang berisi tentang Standard Operating procedure dan tanggung jawab,kualitas pelayanan serta kepuasan tamu.

D. Kuisioner

Menggunakan teknik kuisioner yang tertutup dilakukan pada bulan Mei 2019 sebanyak 30 responden di Grand Edge Hotel Semarang.

\section{Metode Penyajian Data}

Menggunakan metode deskriptif yaitu mendeskripsikan apa-apa yang saat ini berlaku di dalamnya terdapat upaya mencatat analisis, mendeskripsikan dan menginterprestasikan kondisi-kondisi yang sekarang ini terjadi atau ada. (Mardialis, 2006:26). Penulis mendeskripsikan upaya tentang kinerja dari Concierge dengan menjelaskan kondisi tentang prosedur kerja, kualitas pelayanan serta kepuasan tamu.

\section{Metode Analisis Data}

Menggunakan metode analisis data kualitatif. Metode analisis data kualitatif yang dimaksud adalah analisa data mengenai obyek penelitian tanpa menggunakan sistem matematik, statistik, ekonomatrik, atau modelmodel tertentu lainnya. Teknik analisa yang dilakukan penulis adalah membahas data yang diperoleh selama penelitian dengan membandingkan teori-teori yang digunakan dan hasil kuisoner.

\section{HASIL DAN PEMBAHASAN \\ Prosedur Kerja Concierge Grand Edge Hotel Semarang \\ Seorang concierge harus bisa} melaksanakan tugasnya pada jadwal masuk kerja yang sudah dibagikan antara lain:

1. Memberikan pelayanan penanganan barang bawaan tamu tiba, pindah kamar dan tamutamu berangkat. 
2. Memberikan pelayanan penjemputan dan pengantaran tamu dari dan ke stasiun atau bandara.

3. Memberikan pelayanan penyampaian pesan tamu.

4. Memberikan bantuan kepada tamu.

5. Mengantar tamu ke meja pendaftaran.

6. Mengantar tamu ke kamar.

7. Menjaga lobby tetap bersih dan rapi.

8. Melaporkan kejadian-kejadian yang tidak biasa terjadi.

9. Menggudangkan / menangani penitipan barang bawaan tamu.

10. Menjelaskan cara-cara menggunakan beberapa fasilitas yang tersedia di kamar.

Standar Operasional Prosedur Concierge Grand Edge Hotel Semarang

Standar operasional prosedur Concierge di Grand Edge Hotel Semarang pada bulan Mei tahun 2019. Berikut ini adalah tingkat pelayanan yang didasarkan pada 5 indikator pelayanan. Data diperoleh dan diolah dari Front Office Department yang didukung dengan kuisioner yang dibagikan kepada tamu hotel sebagai bahan data penelitian sebanyak 30 responden dengan kriteria sangat puas, puas, cukup puas, tidak puas, dan sangat tidak puas.

\section{Kualitas Pelayanan Concierge Grand Edge} Hotel Semarang

Kualitas pelayanan Concierge di Grand Edge Hotel Semarang pada Mei 2019. Berikut ini adalah tingkat kualitas pelayanan yang didasarkan pada 5 indikator pelayanan. Data diperoleh dan diolah dari Front Office Department yang didukung dengan kuisioner yang dibagikan kepada tamu hotel sebagai bahan data penelitian sebanyak 30 responden dengan kriteria sangat puas, puas, cukup puas, tidak puas, dan sangat tidak puas.

Kepuasan Tamu Terhadap Concierge di Grand Edge Hotel Semarang

Kepuasan tamu terhadap Concierge di Grand Edge Hotel Semarang pada Mei 2019. Berikut ini adalah tingkat pelayanan yang didasarkan pada 5 indikator pelayanan. Data diperoleh dan diolah dari Front Office Department yang didukung dengan kuisioner yang dibagikan kepada tamu hotel sebagai bahan data penelitian sebanyak 30 responden dengan kriteria sangat puas, puas, cukup puas, tidak puas, dan sangat tidak puas.

\section{Pembahasan}

\section{Prosedur Kerja Concierge di Grand Edge Hotel Semarang}

Dari hasil pengamatan penulis selama tiga bulan yaitu dari April - Juni 2019 di Grand Egde Hotel Semarang Berikut prosedur kerja yang diterapkan oleh Grand Edge Hotel Semarang untuk Concierge:

1. Pre Operation (sebelum bekerja) : setelah well groom, melakukan briefing dan hand over pada shift sebelumnya atau selanjutnya. Membaca log book apakah ada sesuatu yang penting untuk concierge, mengecek bahan bakar mobil armada hotel sebelum digunakan, dan membersihkan counter concierge.

2. During Operation (selama bekerja) : stand by di lobi, membantu mengantarkan chief accounting ke bank, membantu vallet parking pada tamu jika ada tamu yang takut untuk memarkirkan mobilnya di basement. Menjemput / mengantarkan tamu ke bandara maupun ke stasiun, membantu tamu check in dan check out, melayani tamu jika ada yang ingin menggunakan rent car.

3. After Operation (setelah bekerja) : setelah bekerja jangan lupa menulis di log book agar shift selanjutnya mengetahui ada berita penting yang di tulis di log book, untuk morning shift setelah bekerja wajib briefing, kemudian untuk middle shift membantu meringankan beban afternoon shift yaitu mencuci salah satu mobil armada hotel, untuk afternoon shift setelah bekerja wajib mengecek KM record seluruh armada mobil hotel. Dan untuk night shift setelah bekerja yaitu hand over dengan morning shift serta menjelaskan apa saja yang harus dikerjakan, dan membersihkan counter concierge.

\section{Standar Operasional Prosedur Concierge Grand Edge Hotel Semarang}

Dari hasil kuisioner yang telah dibuat penulis dan sudah diberikan kepada tamu di Grand Edge Hotel Semarang mengenai standar operasional prosedur pada tanggal 22 - 25 Mei 2019, berikut hasil yang di dapat: 
1. Bellboy Script for Guest Rooming

Dari hasil kuisioner mengenai Bellboy Script for Guest Rooming bahwa tamu Grand Edge Hotel Semarang menyatakan sangat puas dengan persentase $6 \%$, kemudian 52\% menyatakan puas, $36 \%$ menyatakan cukup puas, dan $6 \%$ menyatakan tidak puas.

2. Airline / Train / Bus Reservation

Dari hasil kuisioner mengenai Airline / Train / Bus Reservation bahwa tamu Grand Edge Hotel Semarang menyatakan sangat puas dengan persentase $12,5 \%$, kemudian $64 \%$ menyatakan puas, $22,5 \%$ menyatakan cukup puas, dan $1 \%$ menyatakan tidak puas.

3. Airport Transportation

Dari hasil kuisioner mengenai Airport Transportation bahwa tamu Grand Edge Hotel Semarang menyatakan sangat puas dengan persentase $16 \%$, lalu $38 \%$ menyatakan puas, dan $46 \%$ menyatakan cukup puas.

4. Luggage Handling

Dari hasil kuisioner mengenai Luggage Handling bahwa tamu Grand Edge Hotel Semarang menyatakan sangat puas dengan persentase $12 \%$, lalu $74 \%$ menyatakan puas, dan $14 \%$ menyatakan cukup puas.

5. Luggage Handling 2

Dari hasil kuisioner mengenai Luggage Handling 2 bahwa tamu Grand Edge Hotel Semarang menyatakan sangat puas dengan persentase $12 \%$, lalu $37 \%$ menyatakan puas, dan $51 \%$ menyatakan cukup puas.

6. Lobby Appearance

Dari hasil kuisioner mengenai Lobby Appearance bahwa tamu Grand Edge Hotel Semarang menyatakan sangat puas dengan persentase $3 \%$, lalu $48 \%$ menyatakan puas, $35 \%$ menyatakan cukup puas, dan $13 \%$ menyatakan tidak puas.

7. Luggage Tag

Dari hasil kuisioner mengenai Luggage Tag bahwa tamu Grand Edge Hotel Semarang menyatakan sangat puas dengan persentase $18 \%$, lalu $65 \%$ menyatakan puas, dan $17 \%$ menyatakan cukup puas.

Dari hasil pembahasan di atas, standar operasional prosedur concierge Grand Edge
Hotel Semarang mengacu pada standar operasional prosedur yang dipeoleh dari internet (http://docslide.us/documents/sopconcierge.html\#). bahwa diterapkannya standar operasional prosedur tersebut dapat meningkatkan kerja concierge secara baik dan profesional agar tamu merasa nyaman, aman, dan puas.

\section{Kualitas Pelayanan Concierge di Grand Edge Hotel Semarang}

Berdasarkan hasil penelitian dan pengamatan yang dilakukan penulis pada tanggal 22 - 25 Mei 2019 tentang kualitas pelayanan Concierge di Grand Edge Hotel Semarang memberikan hasil yang baik. Hal ini diperkuat hasil wawancara pada tanggal $24 \mathrm{Mei}$ pukul 10.43 wib dengan Tito Galih Irawan selaku staf concierge Grand Edge Hotel Semarang yang mengatakan bahwa Concierege di Grand Edge Hotel Semarang aktif dalam memberikan pelayanan serta fasilitas yang ada di hotel kepada seluruh tamu tanpa diminta atau disuruh supaya tamu merasa nyaman, aman serta santai selama menginap di hotel. Berikut data dari hasil kuisoner yang diperoleh mengenai kualitas pelayanan, yaitu:

1. Bukti Fisik

Dari hasil kuisioner mengenai bukti fisik concierge bahwa tamu Grand Edge Hotel Semarang menyatakan sangat puas dengan persentase $4 \%$, lalu $30 \%$ menyatakan puas, $62 \%$ menyatakan cukup puas, dan $3 \%$ menyatakan tidak puas.

2. Kehandalan

Dari hasil kuisioner mengenai kehandalan concierge bahwa tamu Grand Edge Hotel Semarang menyatakan sangat puas dengan persentase $27 \%$, lalu $38 \%$ menyatakan puas, 32,5\% menyatakan cukup puas, dan $2,5 \%$ menyatakan tidak puas.

3. Daya Tanggap

Dari hasil kuisioner mengenai daya tanggap concierge bahwa tamu Grand Edge Hotel Semarang menyatakan sangat puas dengan persentase $2,5 \%$, lalu $52,5 \%$ menyatakan puas, $44 \%$ menyatakan cukup puas, dan $1 \%$ menyatakan tidak puas.

4. Jaminan 
Dari hasil kuisioner mengenai jaminan concierge bahwa tamu Grand Edge Hotel Semarang menyatakan sangat puas dengan persentase $12 \%$, lalu $41 \%$ menyatakan puas, dan $47 \%$ menyatakan cukup puas.

5. Empati

Dari hasil kuisioner mengenai empati concierge bahwa tamu Grand Edge Hotel Semarang menyatakan sangat puas dengan persentase $7,5 \%$, kemudian $67 \%$ menyatakan puas, $24 \%$ menyatakan cukup puas, dan $1,7 \%$ menyatakan tidak puas.

Berdasarkan dari hasil data di atas, tamu menggunakan kelima dimensi tersebut sebagai tolok ukur untuk memberikan penilaian terhadap kualitas pelayanan, yaitu yang didasarkan atas perbandingan antara pelayanan yang diharapkan dan kenyataan pelayanan yang diperoleh apakah hasilnya sangat puas, cukup puas, puas, tidak puas, atau sangat tidak puas.

Maka dari itu Concierge di Grand Edge Hotel Semarang selalu berusaha memberikan pelayanan yang terbaik kepada tamu yang menginap. Hal ini sesuai dengan pendapat Lupiyoadi tentang penilaian kualitas pelayanan concierge terhadap tamu. Penilaian yang dimaksud meliputi: Tangibles (bukti fisik), Reliability (kehandalan), Responsiveness (ketanggapan), Assurance (jaminan dan kepastian), Emphaty (empati).

Kepuasan Tamu Terhadap Pelayanan Concierge di Grand Edge Hotel Semarang

Berdasarkan hasil pengamatan dan penelitian penulis pada tanggal $22-25 \mathrm{Mei}$ 2019, Concierge di Grand Edge Hotel Semarang melakukan pelayanan yang dapat meningkatkan kepuasan tamu dengan berbagai macam seperti pelayanan dalam menangani barang bawaan, pelayanan dalam transportasi, pelayanan dalam memberikan informasi, pelayanan dalam memenuhi apa yang dibutuhkan oleh tamu dan lain sebagainya.

Oleh sebab itu, penulis melakukan penelitian dengan menyebarkan kuisioner yang telah dibuat kepada tamu hotel pada tanggal 22 - 25 Mei 2019 tentang kepuasan tamu terhadap pelayanan Concierge di Grand Edge Hotel Semarang. Berikut data yang diperoleh:
Dari hasil kuisioner mengenai kepuasan tamu concierge bahwa tamu Grand Edge Hotel Semarang menyatakan sangat puas dengan persentase $6,7 \%$, lalu $47,5 \%$ menyatakan puas, $45 \%$ menyatakan cukup puas, dan $1 \%$ menyatakan tidak puas. Jadi rata-rata tamu menyatakan puas dengan kepuasan yang diberikan oleh pelayanan concierge.

Berdasarkan hasil data di atas, hampir sama dengan pendapat Lupyoadi mengenai meningkatkan kepuasan tamu, namun ada sedikit yang tidak sesuai. Kepuasan tamu yang dimaksud, yaitu : Kualitas produk, Kualitas pelayanan atau jasa, Emosi, Harga, dan Biaya.

Mengenai kualitas produk, concierge di Grand Edge Hotel Semarang bekerja sama dengan perusahaan VIP Rent Car, tujuannya adalah memberikan kebutuhan kepada tamu hotel jika ingin pergi entah itu hanya sekedar seharian jalan-jalan di kota Semarang, tugas luar kota dan sebagainya.

Namun hanya berbeda di harga dan biaya, sebab Concierge di Grand Edge Hotel Semarang bekerja tanpa mengharapkan pamrih kepada tamu dikarenakan hanya tulus membantu dan saling tolong menolong. Jadi dapat disimpulkan bahwa Concierge bekerja dengan maksimal, profesional dan memberikan rasa aman dan kepercayaan tamu agar merasa puas dengan pelayanan yang diberikan supaya tamu merasa yakin dan ingin menginap kembali ke hotel.

\section{PENUTUP}

\section{Kesimpulan}

Adalah sebagai berikut:

1. Prosedur Kerja Concierge Grand Edge Hotel Semarang

Penerapan prosedur kerja concierge sudah sesuai dengan prosedur kerja yang diterapkan oleh Grand Edge Hotel Semarang. Prosedur kerja yang dimaksud adalah mengenai standar penampilan concierge, pembagian shift jam kerja, kegiatan yang dilakukan sebelum bekerja (pre operation), selama bekerja (during operation), setelah bekerja (after operation). Hasil kuisioner standar operasional kerja concierge, rata-rata tamu menyatakan puas. 
2. Kualitas pelayanan Concierge

Kualitas pelayanan yang dilakukan concierge terhadap tamu sudah cukup apa yang di harapkan. Dari hasil kuisioner ratarata tamu menyatakan cukup puas.

3. Kepuasan tamu terhadap pelayanan Concierge

Pelayanan Concierge yang diberikan dalam meningkatkan kepuasan tamu di Grand Edge Hotel Semarang sudah cukup dengan yang diharapkan. Kepuasan yang dimaksud adalah dengan aktifnya dalam membantu tamu tanpa mengharapkan imbalan.

\section{Saran}

1. Pertahankan prosedur kerja agar lebih profesional serta tingkatkan kedisiplinan, penampilan, kebersihan dan tanggung jawab kerja sesuai dengan peraturan yang ada.

2. Tingkatkan keramah-tamahan, senyum, salam, dan sapa dalam melakukan pekerjaan serta komunikasi yang baik terutama ditujukan untuk membangun kerja yang disiplin dan saling menghargai satu sama lain supaya tidak terjadi hubungan yang tidak harmonis.

\section{DAFTAR PUSTAKA}

[1] Arief. 2005. Pengantar Ilmu Perhotelan dan Restoran. Yogyakrta: Penerit Graha Ilmu.

[2] Darsono, Agustinus. 2001. Kantor Depan Hotel. Jakarta: PT. Gramedia.

[3] Dimyati, Aan Surachlan. 1989. Pengetahuan Dasar Perhotelan. Jakarta: CV Deviri Ganan.

[4] Hasan, Iqbal. 2004. Anlisis Data Penelitian Dengan Statistik. Cetakan ke-2. Jakarta: PT. Gramedia Pustaka Utama.

[5] http://apkexcellent.blogspot.co.id/2013/06 /konsep-dasar-pelayanan-prima.html.

[6] http://docslide.us/documents/sopconcierge.html\#

[7] Lupiyoadi, Rambat. 2001. Manajemen Pemasaran Jasa. Edisi Pertama. Salemba Empat: Jakarta

[8] Mardialis. 2006. Metode Penelitan. Jakarta: PT. Bumi Aksara.
[9] Ratminto dan Atik Winarsih. 2005. Manajemen Pelayanan. Pustaka Pelajar: Yogyakarta

[10] Sambodo dan Bagyono. 2006. Dasar-Dasar Kantor Depan Hotel. Yogyakarta: Penerbit Andi.

[11] Sihite, Richard. 2000. Front Office. Surabaya: SIC.

[12] Suarthana. 2006. Manajemen Perhotelan edisi Kantor Depan. Kuta Utara: Mapindo

[13] Sugiarto, Endar. 2002. Psikologi Pelayanan Dalam Industri Jasa. Jakarta: Gramedia Pustaka Utama.

[14] Sugiarto, Kusmayadi. 2000. Metodologi Penelitian Dalam Bidang Kepariwisataan. Jakarta: PT. Gramedia Pustaka Utama.

[15] Sulastiyono, Agus. 2001. Manajemen Penyelenggaraan Hotel. Bandung: Alfabeta CV.

[16] Suwarman ， Ujang. 2003. Perilaku Konsume: Teori dan Penerapannya dalam Pemasaran. Jakarta: Ghalia Indonesia 